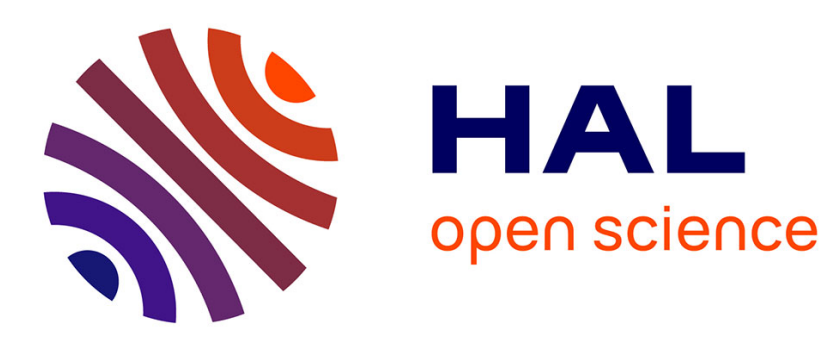

\title{
A multi-scale analysis of the mechanical behavior of thermo-oxidized C/epoxy lamina
}

Ahmed Yousfi, Sylvain Fréour, Frédéric Jacquemin, Mohamed Rahmani, H. Osmani, Ronald Guillén

\section{> To cite this version:}

Ahmed Yousfi, Sylvain Fréour, Frédéric Jacquemin, Mohamed Rahmani, H. Osmani, et al.. A multiscale analysis of the mechanical behavior of thermo-oxidized C/epoxy lamina. Mechanics of Composite Materials, 2010, 46 (1), pp.101-112. 10.1007/s11029-010-9130-5 . hal-01004855

\section{HAL Id: hal-01004855 https://hal.science/hal-01004855}

Submitted on 22 Nov 2018

HAL is a multi-disciplinary open access archive for the deposit and dissemination of scientific research documents, whether they are published or not. The documents may come from teaching and research institutions in France or abroad, or from public or private research centers.
L'archive ouverte pluridisciplinaire HAL, est destinée au dépôt et à la diffusion de documents scientifiques de niveau recherche, publiés ou non, émanant des établissements d'enseignement et de recherche français ou étrangers, des laboratoires publics ou privés. 


\title{
A MULTISCALE ANALYSIS OF THE MECHANICAL BEHAVIOR OF A THERMO-OXIDIZED C/EPOXY LAMINA
}

\author{
A. Yousfi, ${ }^{a}$ S. Fréour, ${ }^{b}, *$ F. Jacquemin, ${ }^{b}$ \\ M. Rahmani, ${ }^{\text {a }}$ H. Osmani, ${ }^{\mathrm{c}}$ \\ and R. Guillén ${ }^{b}$
}

Keywords: thermo-oxidation, polymer matrix composites, scale transition models, local stresses

\begin{abstract}
The mechanical behavior of carbon-fiber-reinforced polymer matrix composites having undergone a thermo-oxidation process is studied. The purpose is to perform a multiscale analysis of the consequences of oxidation on the intrinsic mechanical properties of the external composite ply and on the internal mechanical states experienced by the structure under mechanical loads. The effective mechanical properties of oxidized composite plies are determined according to the Eshelby-Kröner self-consistent homogenization procedure, depending on evolution of the oxidation process. The results obtained are compared with estimates found by the finite-element method. The macroscopic mechanical states are calculated for a unidirectional composite and laminates. The macroscopic stresses in each ply of the structure are determined by the classical lamination theory and the finite-element method, whereas the local stresses in the carbon fiber and epoxy matrix are calculated by using an analytical stress concentration relation.
\end{abstract}

\section{Introduction}

Due to their very interesting specific mechanical properties, carbon-reinforced epoxy laminates are considered as serious candidates for the replacement of metals, metallic alloys, and cermets for various industrial applications, including the structural parts for the next-generation supersonic aircrafts [1]. The lifetime scheduled for the structural elements of supersonic aircraft approximately corresponds to 20,000 cycles in a range of temperatures varying between -55 and $120^{\circ} \mathrm{C}$, with a total length of the plateau of $80,000 \mathrm{~h}\left(20\right.$ years) at $120^{\circ} \mathrm{C}$ [2]. Such high temperatures over long periods of time cause thermal aging of the constitutive resin of composite structural elements. Before 1990, few studies have been conducted on the thermal aging of organic-matrix composites reinforced with carbon fibers. Before this date, the use of these materials had been limited to rather low temperatures, between -50 and $+70^{\circ} \mathrm{C}$, which correspond to the thermal loads experienced in service by structural parts of, for example, subsonic aircraft and helicopters. Nevertheless, some important pioneering work had been performed [3-5]. Recently, the problem arose when such organic-matrix composites were considered for use under severe thermal envi-

${ }^{\mathrm{a}}$ Department of Mechanical Engineering, University of Laghouat, Algeria. ${ }^{\mathrm{b}} \mathrm{GeM}$, Institut de Recherche en Génie -Civil et Mécanique, UMR CNRS 6183, Université de Nantes, Ecole Centrale de Nantes, France. ${ }^{\circ}$ Nonmetallic Materials Laboratory, University of Setif, Algeria. Russian translation published in Mekhanika Kompozitnykh Materialov, Vol. 46, No. 1, pp. 139-156, January-February, 2010. Original article submitted June 4, 2009.

*Corresponding author; e-mail: sylvain.freour@univ-nantes.fr 
ronmental conditions (at temperatures of about $250^{\circ} \mathrm{C}$ and air pressure higher than $1 \mathrm{~atm}$ ) [6,7]. It is now well established that, when exposed to high temperatures in air, organic-matrix composites perish by thermal oxidation of the matrix, which leads to shrinkage of the skin layer of laminates, the appearance of high local stresses, and matrix cracking [3, 8-10]. The key feature of this aging process is the fact that the degradation is nonuniform in the material thickness, because the oxidation is diffusion-controlled. In the last 20 years, many attempts have been made to model these degradation gradients and thus to obtain a realistic description of thermal aging of the organic matrix. Some authors have contributed to this research by deriving a kinetic model coupling the oxygen reaction and diffusion from a radical chain oxidation mechanism [11].

For every instant of time $t$, the model predicts various physicochemical characteristics, e.g., the weight and density, of every elementary layer located at a depth $x$ beneath the sample surface [11]. The knowledge of both the quantities enables one to determine the matrix volume change (oxidation-induced "hindered" shrinkage of thick parts), which is thought to generate the stress state responsible for cracking of the external plies [12] of a composite structure. But this volume change can be predicted only if the local mechanical properties of the structure are known. More recently, it was shown that a second important consequence of thermal aging in epoxy networks is a decrease in the glass-transition temperature $\left(T_{\mathrm{g}}\right)$, which is linked to chain scission, and an increase in the glassy modulus at ambient temperature, which is attributed to the effect of internal antiplasticization [13]. Nonempirical relationships linking the local structural state of epoxy network to the resulting glassy modulus are still under development [13]. Fortunately, empirical relationships have been proposed [14, 15], and they will be considered here as a first approach.

The purpose of this study is to perform a multiscale analysis of consequences of the thermal oxidation and shrinkage of epoxy matrices on the intrinsic mechanical properties of the external composite ply and on the internal mechanical states of the composite under mechanical loads.

\section{Effective Properties of a Thermo-Oxidized Composite Ply}

1.1. Oxidation model and results. Various models for numerically computing the oxidation process in pure epoxies or epoxy matrix composites have been proposed in the literature $[15,16]$. Simulations of the isothermal aging of an epoxy resin at $150^{\circ} \mathrm{C}$ for various lengths of aging period showed that the oxidized layer thickness did not excess $200 \mu \mathrm{m}$, whereas the concentration of oxidation products increased continuously in the affected layer [17]. The average depths of matrix shrinkage in specimens held for 400 and $600 \mathrm{~h}$ at $150^{\circ} \mathrm{C}$ in air were close $(\sim 1.5 \mu \mathrm{m})$, but they were smaller than those in samples submitted to 500 thermal cycles $(2.2 \mu \mathrm{m})$ [18]. The results obtained in ultramicro indentation tests on epoxy resin, after 100, 600, and $1000 \mathrm{~h}$ of isothermal aging at $150^{\circ} \mathrm{C}$, showed that the relationship between the elastic modulus and the concentration of oxidation products could be described by the empirical formula [17]

$$
Y^{\mathrm{m}}=5479-1460 \exp (-0.79 Q)
$$

where $Y^{\mathrm{m}}$ is the elastic modulus of epoxy matrix in $\mathrm{MPa}$ and $Q$ is the concentration of oxidation products in mol/L. It must be underlined here that relationship (1) is not rigorously based on theoretical concepts. It has been obtained by fitting a combination of experimental and theoretical results and is valid for the temperature considered $\left(150^{\circ} \mathrm{C}\right)$. The evolution of Young's modulus of the matrix during the thermal oxidation process is displayed in Fig. 1. The matrix is considered as an isotropic material. Because of the lack of available information on the evolution of its Poisson's ratio $v^{\mathrm{m}}$ during the process of thermal oxidation, it is assumed constant and equal to 0.35 , but the shear modulus is found from the classical relation

$$
G^{\mathrm{m}}=\frac{Y^{\mathrm{m}}}{2\left(1+Y^{\mathrm{m}}\right)} .
$$

The thermally oxidized matrix is up to 1.38 times stiffer than the unaffected one; therefore, three main consequences of thermal oxidation of composites can be expected: a variation in (i) the effective macroscopic properties of composite plies, (ii) the profiles of macroscopic stress in the structure, and (iii) the localization of macroscopic mechanical stress and strain 


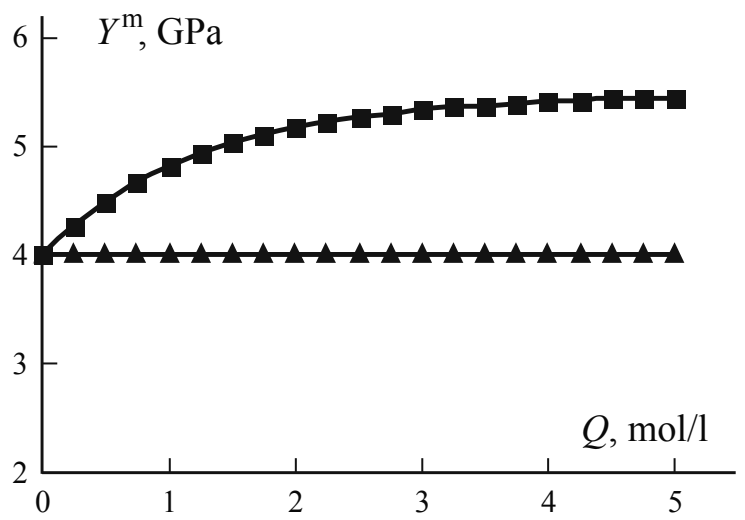

Fig. 1. Elastic modulus $Y^{\mathrm{m}}$ of oxidized ( $\left.\mathbf{\square}\right)$ and unaffected $(\mathbf{\Delta})$ matrices vs. concentration $Q$ of oxidation products.

states in both its constituents (fiber and matrix) of each ply. The three expected consequences of thermo-oxidation are multiscale phenomena, which show up either explicitly, as in the cases (i) (the homogenization problem) and (iii) (the localization problem), or implicitly, as in the case (ii), which implies the knowledge of the macroscopic effective properties of the composite ply. In order to treat each of these points, a scale transition model is required. This model is described below.

\section{Multiscale Analysis}

2.1. Introduction. Scale transition models are based on a multiscale representation of materials. In the case of composite materials, the following two-scale model is sufficient.

- The properties and mechanical states of the resin and its reinforcement, which are indicated by the superscripts " $\mathrm{m}$ " and "r," respectively, define the so-called "pseudo-macroscopic" scale of the material [19].

- The homogenization operations performed over its constituents are assumed to provide the effective mechanical characteristics of the composite ply, labeled with the superscript "I," which define the macroscopic scale of the model. This definition also enables one to consider a unidirectional reinforcement at the macroscopic scale.

The laminate is a combination of the above-described unidirectional composite plies, which can be oriented differently. In the scale transition modeling, the local properties of i-superscribed constituents [i.e., the pseudomacroscopic stiffnesses $\mathbf{L}^{\mathrm{i}}$ and the coefficients of thermal expansion (CTE) $\mathbf{M}^{\mathrm{i}}$ ] are usually considered known, whereas the corresponding effective macroscopic properties of the composite, $\mathbf{L}^{\mathrm{I}}$ and $\mathbf{M}^{\mathrm{I}}$, are a priori unknown and are obtained from (often numerical) computations.

Among the numerous, available in the literature, scale transition models able to handle such a problem, the models proposed by Voigt [20], Reuss, [21], Neerfeld-Hill [22, 23], Tsai-Hahn [24], and Mori-Tanaka [25, 26] can be mentioned.

But they do not properly reflect the real physical conditions experienced in practice by the material. In spite of the lack of physical realism, some of the aforementioned models do nevertheless provide satisfactory estimates for the effective properties of a composite ply, by comparison with experimental data or results from other, more rigorous models. The Tsai-Hahn and Mori-Tanaka models both fulfil this interesting condition [27, 28]. However, in the field of scale transition modeling, the best candidate remains the Kröner-Eshelby self-consistent model [29, 30], because only this model takes into account the thermohygroelastic interactions between the homogeneous macroscopic matrix and its heterogeneous constituents and considers the particular morphology of the constituents.

It should also be underlined that, in the above-cited models, at the smallest scale considered (the base volume of heterogeneities, i.e., the pseudomacroscopic scale in the present study), the properties of materials are uniform. This means that, in order to perform simulations, it is necessary to assume that the matrix of the surface ply has uniform properties across its thickness, which is contrary to the facts described in the literature [17]. 

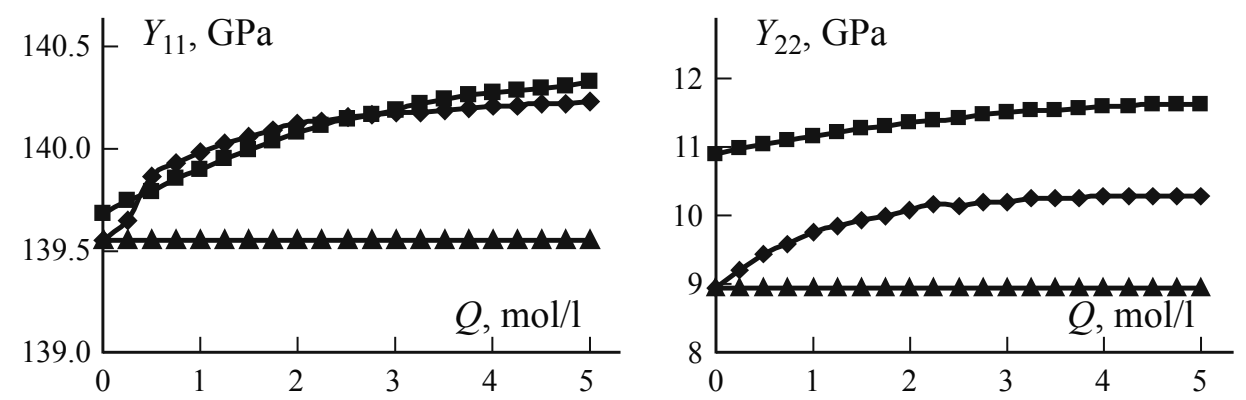

Fig. 2. Effective macroscopic longitudinal $Y_{11}$ (à) and transverse $Y_{22}$ (b) elastic moduli of an unaffected composite ply $(\boldsymbol{\Delta})$ and its variation in relation to $Q$ for an oxidized ply calculated by Eq. (2) ( $\bullet)$ and the FEM $(\mathbf{\square})$.

2.2. Determination of the effective macroscopic thermoelastic properties of composite plies. According to the Eshelby-Kröner self-consistent model, the homogenization relation enabling one to determine the macroscopic elastic stiffness of a composite ply from the properties of its constituents is

$$
\mathbf{L}^{\mathrm{I}}=\left\langle\mathbf{L}^{\mathrm{i}}:\left[\mathbf{E}^{\mathrm{I}}:\left(\mathbf{L}^{\mathrm{i}}-\mathbf{L}^{\mathrm{I}}\right)+\mathbf{I}\right]^{-1}\right\rangle_{\mathrm{i}=f, m} .
$$

Here, I stands for the fourth-order identity tensor, whereas the name given to the tensor $\mathbf{E}^{\mathrm{I}}$ often changes from one article to another (it is called, for example, the Hill or Morris tensor, depending on which study, [31] or [32], is considered). It can be expressed as $\mathbf{E}^{\mathrm{I}}=\mathbf{S}_{\text {Esh }}^{\mathrm{I}}: \mathbf{L}^{\mathrm{I}^{-1}}$, where $\mathbf{S}_{\text {Esh }}^{\mathrm{I}}$ is the Eshelby tensor. It has to be underlined that both the Hill and the Eshelby tensor components are functions of the macroscopic stiffness $\mathbf{L}^{\mathbf{I}}$ (some examples are given in $[33,34]$ ).

The homogenization relation satisfied by the macroscopic CTE of a composite ply has the form

$$
\mathbf{M}^{\mathrm{I}}=\mathbf{L}^{\mathrm{I}^{-1}}:\left\langle\left[\mathbf{E}^{\mathrm{I}}:\left(\mathbf{L}^{\mathrm{i}}-\mathbf{L}^{\mathrm{I}}\right)+\mathbf{I}\right]^{-1}: \mathbf{L}^{\mathrm{i}}: \mathbf{M}^{\mathrm{i}}\right\rangle_{\mathrm{i}=f, m} .
$$

Only few studies have been dedicated to the oxidation effects on the mechanical behavior of organic-matrix composites $[15,35,36]$. It was shown in [37] that the properties of carbon fibers are stable below $300^{\circ} \mathrm{C}$. As a consequence, the variations in the mechanical properties of thermo-oxidized laminates depend only on the evolution of matrix properties. In our calculations, the following local properties of the T300 carbon fiber were used [38]: $Y_{1}=230 \mathrm{GPa}, Y_{2}=Y_{3}=15 \mathrm{GPa}, v_{12}=v_{13}=$ $0.2, G_{12}=15 \mathrm{GPa}$, and $G_{23}=7 \mathrm{GPa}$.

The effective longitudinal and transverse macroscopic elastic moduli vs. concentration of oxidation products are shown in Fig. 2 for a composite with 60 vol.\% carbon fibers. The evolution of the effective mechanical properties of the composite ply in the course of oxidation was determined by using the Eshelby-Kröner self-consistent homogenization procedure (Eq. 3). The results are compared with the corresponding estimates found according to the finite-element method.

Figure 3 shows the evolution of the effective macroscopic coefficients of thermal expansion according to Eq. (3). In the computations, the following pseudomacroscopic CTEs were used: $M_{11}^{\mathrm{m}}=M_{22}^{\mathrm{m}}=M_{33}^{\mathrm{m}}=60 \cdot 10^{-6} \mathrm{~K}^{-1}, M_{11}^{\mathrm{f}}=-0.7 \cdot 10^{-6} \mathrm{~K}^{-1}$, and $M_{22}^{\mathrm{f}}=M_{33}^{\mathrm{f}}=12 \cdot 10^{-6} \mathrm{~K}^{-1}$. Since the literature does not report the evolution of CTE during oxidation process of the matrix, the pseudomacroscopic CTEs considered in the present study are obviously those of unaffected constituents, as given in [38].

According to Figs. 2 and 3, the longitudinal effective properties of the composite ply (i.e., in the direction of reinforcing fibers), in a first approximation, are independent of the state of thermal oxidation process of the polymer matrix. Indeed, a relative deviation smaller than $1 \%$ is observed for Young's modulus at the end of the oxidation process, while the longitudinal macroscopic coefficient of thermal expansion remains almost constant. This result is explained by the fact that, in the fiber di- 

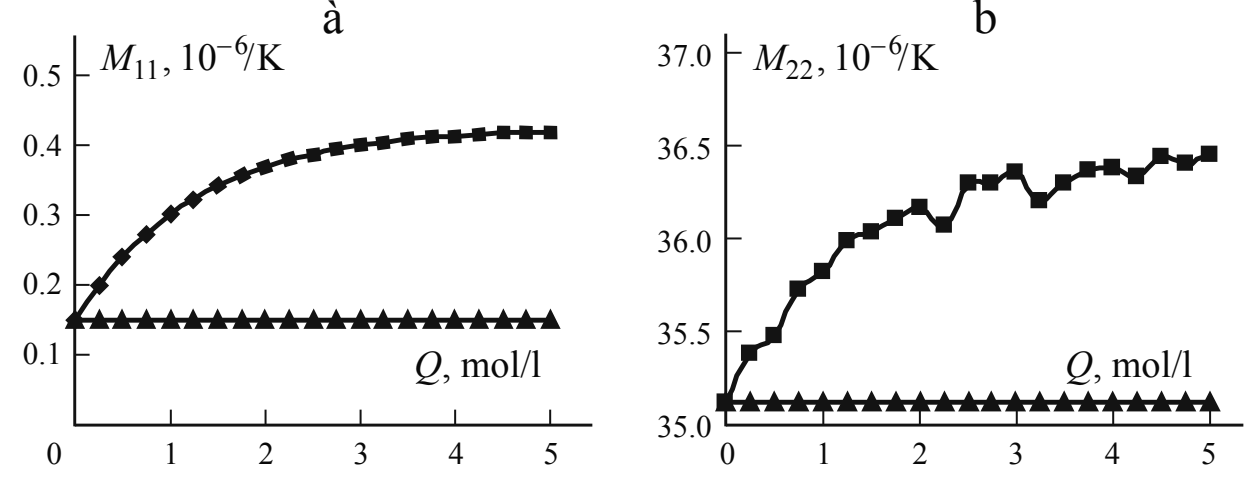

Fig. 3. The effective mactroscopic longitudinal $M_{11}$ (à) and transverse $M_{22}$ (b) coefficients of thermal expansion of oxidized $(\boldsymbol{\square})$ and unaffected $(\mathbf{\Lambda})$ plies.

rection, the thermomechanical properties of the plies are determined mainly by properties of the fibers. The experimental data obtained for composite plies in the cases where carbon fibers exhibit constant properties, while those of the matrix vary significantly, corroborates the results of our simulations: the longitudinal effective macroscopic properties of composite plies do not depend on the properties of polymer matrix (at least at high volume fractions of fibers) [39]. On the contrary, the effective macroscopic properties of a composite ply in the transverse direction are greatly affected by the thermal oxidation process proceeding in the polymer matrix constituting the ply. In fact, the relative variation in the transverse Young's modulus of an oxidized ply, as compared with the reference value (for an unaffected ply), can reach $12 \%$ at the end of oxidation process (the variation in the transverse coefficient of thermal expansion can run to 3.5\%). The reader will notice that this variation depends on the volume fraction of reinforcement in a composite ply.

\section{Study of the Multiscale Mechanical States Experienced by the}

\section{Composite Structure}

3.1. Effect of matrix shrinkage on the mechanical states of the thermo-oxidized composite. The oxidation of epoxy matrix results in a mass loss and a reduced volume of the matrix, inducing shrinkage of this constituent with respect to fibers [40]. As a consequence of matrix shrinkage, the high strain gradients that arise in matrix areas close to fibers having a very high stiffness create high local stresses, which can lead to fiber debonding and initiation of matrix cracking [41]. The total strain $\varepsilon_{t}^{m}$ in the matrix is

$$
\boldsymbol{\varepsilon}_{\mathrm{t}}^{\mathrm{m}}=\varepsilon_{\mathrm{e}}^{\mathrm{m}}+\boldsymbol{\varepsilon}_{\mathrm{sh}}^{\mathrm{m}},
$$

where $\varepsilon_{\mathrm{e}}^{\mathrm{m}}$ is the elastic strain and $\varepsilon_{\mathrm{sh}}^{\mathrm{m}}$ is the strain due to the shrinkage of matrix, which depends on its oxidation state and has the form

$$
\varepsilon_{\mathrm{sh}}^{\mathrm{m}}=\left[\begin{array}{ccc}
\delta_{11}^{\mathrm{m}} & 0 & 0 \\
0 & \delta_{11}^{\mathrm{m}} & 0 \\
0 & 0 & \delta_{11}^{\mathrm{m}}
\end{array}\right] Q
$$

Here, $\delta_{11}^{\mathrm{m}}=\frac{\varepsilon_{\mathrm{sh}}\left(Q_{\max }\right)}{Q_{\max }}$, and $\varepsilon_{\mathrm{sh}}\left(Q_{\max }\right)=2.5 \%$ is the maximal strain due to matrix shrinkage [42].

3.2. Determination of mechanical states in the constituents of a composite ply subjected to thermoelastic loading. Analytical relations satisfying the fundamental assumptions of the Eshelby-Kröner self-consistent model and enabling 


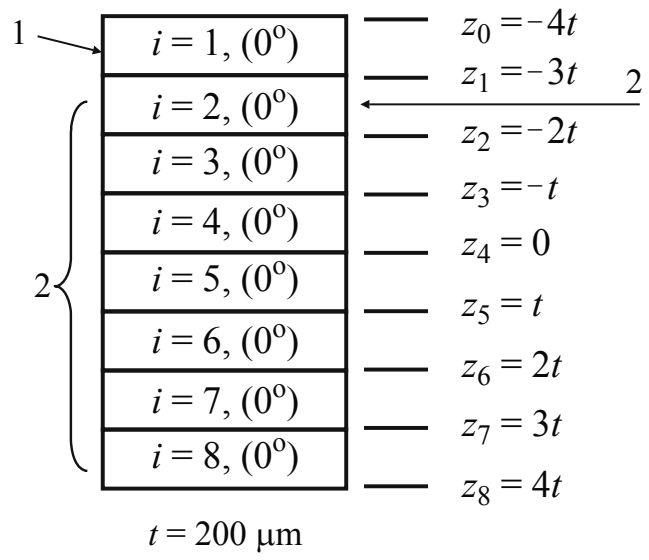

Fig. 4. Schematic sketch of the composite plate with oxidized (1) and unaffected (2) plies considered in computations.

one to calculate the macroscopic strains in the matrix were established in [43] in the case where the material was subjected to a hygroelastic load. Since these relations are lengthy, they are not given in the present work, and an interested reader is referred to Eqs. (19)-(20) in [43]. In these equations, $\beta$ stands for the coefficient of moisture expansion and $\Delta C$ is the moisture content, which, in scale transition modeling, contrary to temperature, is generally considered heterogeneous in a given ply, so that $\Delta C^{\mathrm{I}} \neq \Delta C^{\mathrm{m}} \neq \Delta C^{\mathrm{f}}$. Introducing the replacements $\beta_{11}^{\mathrm{m}} \rightarrow M_{11}^{\mathrm{m}}, \beta_{11}^{\mathrm{r}} \rightarrow M_{11}^{\mathrm{r}}, \beta_{22}^{\mathrm{r}} \rightarrow M_{22}^{\mathrm{r}}, \beta_{11}^{\mathrm{I}} \rightarrow M_{11}^{\mathrm{I}}, \beta_{22}^{\mathrm{I}} \rightarrow M_{22}^{\mathrm{I}}$, $\Delta C^{\mathrm{I}} \rightarrow \Delta T^{\mathrm{I}}$, and $\Delta C^{\mathrm{m}} \rightarrow \Delta T^{\mathrm{m}}$ in the equations and assuming a uniform distribution of temperature in constituents of the ply (i.e., $\Delta T^{\mathrm{I}}=\Delta T^{\mathrm{m}}=\Delta T^{\mathrm{f}}$ ), we arrive at the following analytical relations for the macroscopic strains in the matrix of a unidirectional fiber-reinforced ply:

$$
\begin{gathered}
\varepsilon_{11}^{\mathrm{m}}=\varepsilon_{11}^{\mathrm{I}}, \quad \varepsilon_{12}^{\mathrm{m}}=\frac{2 L_{55}^{\mathrm{I}} \varepsilon_{12}^{\mathrm{I}}}{L_{55}^{\mathrm{I}}+L_{44}^{\mathrm{m}}}, \quad \varepsilon_{13}^{\mathrm{m}}=\frac{2 L_{55}^{\mathrm{I}} \varepsilon_{13}^{\mathrm{I}}}{L_{55}^{\mathrm{I}}+L_{44}^{\mathrm{m}}}, \varepsilon_{22}^{\mathrm{m}}=\frac{N_{1}^{\mathrm{m}}+N_{2}^{\mathrm{m}}+N_{3}^{\mathrm{m}}+N_{4}^{\mathrm{m}}}{D_{1}^{\mathrm{m}}}, \\
\varepsilon_{23}^{\mathrm{m}}=\frac{2 L_{22}^{\mathrm{I}}\left(L_{22}^{\mathrm{I}}-L_{23}^{\mathrm{I}}\right) \varepsilon_{23}^{\mathrm{I}}}{2 L_{22}^{\mathrm{I}^{2}}+L_{23}^{\mathrm{I}}\left(L_{44}^{\mathrm{I}}-L_{44}^{\mathrm{m}}\right)+L_{22}^{\mathrm{I}}\left(3 L_{44}^{\mathrm{m}}-2 L_{23}^{\mathrm{I}}-3 L_{44}^{\mathrm{I}}\right)}, \\
\varepsilon_{33}^{\mathrm{m}}=\varepsilon_{22}^{\mathrm{m}}-4 L_{22}^{\mathrm{I}} \frac{\left(L_{22}^{\mathrm{I}}-L_{23}^{\mathrm{I}}\right)\left(\varepsilon_{22}^{\mathrm{I}}-\varepsilon_{33}^{\mathrm{I}}\right)}{L_{22}^{\mathrm{I}^{2}}+3 L_{22}^{\mathrm{I}}\left(L_{11}^{\mathrm{m}}-L_{12}^{\mathrm{m}}\right)-L_{23}^{\mathrm{I}}\left(L_{11}^{\mathrm{m}}+L_{23}^{\mathrm{I}}-L_{12}^{\mathrm{m}}\right)},
\end{gathered}
$$

where

$$
\begin{gathered}
N_{1}^{\mathrm{m}}=M_{11}^{\mathrm{m}}\left(L_{11}^{\mathrm{m}}+2 L_{12}^{\mathrm{m}}\right) \Delta T-\left[M_{11}^{\mathrm{I}} L_{12}^{\mathrm{I}}+M_{22}^{\mathrm{I}}\left(L_{22}^{\mathrm{I}}+L_{23}^{\mathrm{I}}\right)\right] \Delta T, \\
N_{2}^{\mathrm{m}}=\left(L_{12}^{\mathrm{I}}+L_{12}^{\mathrm{m}}\right) \varepsilon_{11}^{\mathrm{I}}, \\
N_{3}^{\mathrm{m}}=\frac{L_{22}^{\mathrm{I}}\left[L_{22}^{\mathrm{I}}\left(5 L_{11}^{\mathrm{m}}-L_{12}^{\mathrm{m}}+3 L_{22}^{\mathrm{I}}\right)-L_{23}^{\mathrm{I}}\left(3 L_{11}^{\mathrm{m}}+L_{12}^{\mathrm{m}}+4 L_{22}^{\mathrm{I}}\right)+L_{23}^{\mathrm{I}^{2}}\right]}{\left(3 L_{22}^{\mathrm{I}}-L_{23}^{\mathrm{I}}\right)\left(L_{11}^{\mathrm{m}}-L_{12}^{\mathrm{m}}\right)+L_{22}^{\mathrm{I}^{2}}-L_{23}^{\mathrm{I}^{2}}} \varepsilon_{22}^{\mathrm{I}}, \\
N_{4}^{\mathrm{m}}=\frac{L_{22}^{\mathrm{I}}\left[L_{22}^{\mathrm{I}}\left(L_{11}^{\mathrm{m}}-5 L_{12}^{\mathrm{m}}+L_{22}^{\mathrm{I}}\right)-L_{23}^{\mathrm{I}}\left(L_{11}^{\mathrm{m}}+3 L_{12}^{\mathrm{m}}+4 L_{22}^{\mathrm{I}}\right)+3 L_{23}^{\mathrm{I}^{2}}\right]}{\left(3 L_{22}^{\mathrm{I}}-L_{23}^{\mathrm{I}}\right)\left(L_{11}^{\mathrm{m}}-L_{12}^{\mathrm{m}}\right)+L_{22}^{\mathrm{I}^{2}}-L_{23}^{\mathrm{I}^{2}}} \varepsilon_{33}^{\mathrm{I}},
\end{gathered}
$$




$$
D_{1}^{\mathrm{m}}=L_{11}^{\mathrm{m}}+L_{12}^{\mathrm{m}}+L_{22}^{\mathrm{I}}-L_{23}^{\mathrm{I}} .
$$

The corresponding stress tensor in the matrix can be deduced from its strain state:

$$
\sigma^{\mathrm{m}}=\left[\begin{array}{ccc}
\sigma_{11}^{\mathrm{m}} & 2 L_{44}^{\mathrm{m}} \varepsilon_{12}^{\mathrm{m}} & 2 L_{44}^{\mathrm{m}} \varepsilon_{13}^{\mathrm{m}} \\
2 L_{44}^{\mathrm{m}} \varepsilon_{12}^{\mathrm{m}} & \sigma_{22}^{\mathrm{m}} & 2 L_{44}^{\mathrm{m}} \varepsilon_{23}^{\mathrm{m}} \\
2 L_{44}^{\mathrm{m}} \varepsilon_{13}^{\mathrm{m}} & 2 L_{44}^{\mathrm{m}} \varepsilon_{23}^{\mathrm{m}} & \sigma_{33}^{\mathrm{m}}
\end{array}\right],
$$

where

$$
\begin{aligned}
& \sigma_{11}^{\mathrm{m}}=L_{11}^{\mathrm{m}} \varepsilon_{11}^{\mathrm{m}}+L_{12}^{\mathrm{m}}\left(\varepsilon_{22}^{\mathrm{m}}+\varepsilon_{33}^{\mathrm{m}}\right)-M_{11}^{\mathrm{m}}\left(L_{11}^{\mathrm{m}}+2 L_{12}^{\mathrm{m}}\right) \Delta T, \\
& \sigma_{22}^{\mathrm{m}}=L_{11}^{\mathrm{m}} \varepsilon_{22}^{\mathrm{m}}+L_{12}^{\mathrm{m}}\left(\varepsilon_{11}^{\mathrm{m}}+\varepsilon_{33}^{\mathrm{m}}\right)-M_{11}^{\mathrm{m}}\left(L_{11}^{\mathrm{m}}+2 L_{12}^{\mathrm{m}}\right) \Delta T, \\
& \sigma_{33}^{\mathrm{m}}=L_{11}^{\mathrm{m}} \varepsilon_{33}^{\mathrm{m}}+L_{12}^{\mathrm{m}}\left(\varepsilon_{11}^{\mathrm{m}}+\varepsilon_{22}^{\mathrm{m}}\right)-M_{11}^{\mathrm{m}}\left(L_{11}^{\mathrm{m}}+2 L_{12}^{\mathrm{m}}\right) \Delta T .
\end{aligned}
$$

The mechanical states in the reinforcement can be found from the Hill relations [31]

$$
\sigma^{\mathrm{f}}=\frac{1}{v^{\mathrm{f}}} \sigma^{\mathrm{I}}-\frac{v^{\mathrm{m}}}{v^{\mathrm{f}}} \sigma^{\mathrm{m}}, \quad \varepsilon^{\mathrm{f}}=\frac{1}{v^{\mathrm{f}}} \varepsilon^{\mathrm{I}}-\frac{v^{\mathrm{m}}}{v^{\mathrm{f}}} \varepsilon^{\mathrm{m}} .
$$

In the present study, we consider a thin laminated (0/-0) plate of thickness $1600 \mu \mathrm{m}$, composed of 8 plies, as shown in Fig. 4. The oxidation process is assumed to occur only from one edge of the plate and to affect only the first (external) ply.

The variations in the internal macroscopic stresses $\sigma_{11}^{\mathrm{I}}$ and $\sigma_{22}^{\mathrm{I}}$ during the oxidation process of the composite laminate subjected to longitudinal tension $\left(\sigma_{11}=100 \mathrm{MPa}\right)$, transverse tension $\left(\sigma_{22}=50 \mathrm{MPa}\right)$, or shear stress $\left(\sigma_{12}=25 \mathrm{MPa}\right)$ were calculated. A similar calculation was performed for the plate in a pure thermal loading with $\Delta T=100^{\circ} \mathrm{C}$. The results obtained for the macroscopic mechanical states were localized in constituents of the plate using the foregoing scale transition relations. The curves for both the macroscopic and the local stresses in the external ply are displayed in Figs. 5-8. The figures show the stress states in the thermo-oxidized and unaffected laminates calculated by employing the Eshelby-Kröner self-consistent model and a finite-element analysis (using the Matlab software).

Figures 5 to 8 underline the following effects, predicted by the present approach, of thermal oxidation on the multiscale mechanical states in an oxidized ply and its first neighbor.

(i) If a composite is submitted to a longitudinal external load, the multiscale internal stresses in the oxidized ply do not depend on the state of oxidation process. This result can be explained by the fact that the oxidation state does not affect the macroscopic effective properties of the composite in the longitudinal direction (see Sect. 3 of the present study).

(ii) In an oxidation-free unidirectionally reinforced composite submitted to a uniform thermal load, no stresses arise at the ply scale. The situation is very similar in the case of a partially (i.e., partially in depth) oxidized structure. Small stresses arise in the first and second plies of the oxidized structure due to their heterogeneous thermomechanical properties. This is the result of the relatively weak evolution of the macroscopic effective coefficients of thermal expansion predicted by the present approach (according to Fig. 3). Nevertheless, it should be underlined that the data used in the present study to account for the influence of thermal oxidation and matrix shrinkage on the effective properties of composite plies do not involve pseudomacroscopic CTE (especially those of the epoxy), which themselves depend on the oxidation state, due to the lack of available published experimental results. Therefore, the results of numerical simulations displayed in Fig. 8 should be considered only as preliminary, and the conclusions drawn from them could be revised if the true pseudomacroscopic thermomechanical properties of thermo-oxidized epoxies had been investigated more extensively in the literature. We mention in passing that the most significant factor in the thermo-oxidation of resins - the shrinkage due to the release of oxidation by-products - has been accounted for in the present manuscript. Actually, the shrinkage is eventually manifested as the rise of 

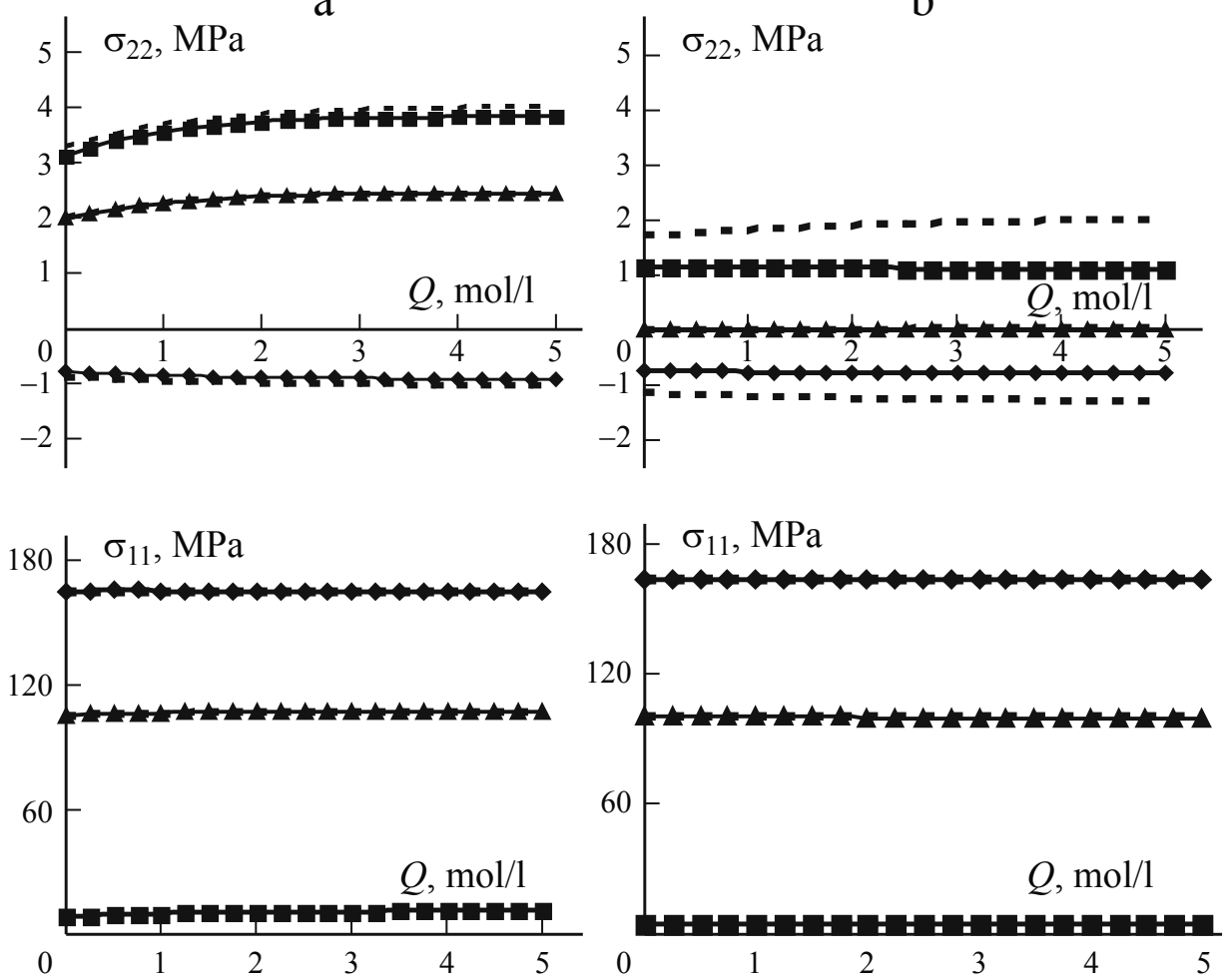

Fig. 5. Longitudinal $\sigma_{11}$ and transverse $\sigma_{22}$ stresses in oxidized (a) and unaffected (b) external plies $(\boldsymbol{\Delta})$ and in their fibers $(\diamond)$ and matrix $(\square)$ vs. $Q$ calculated by the scale transition method and the same by using the FEM (- - -). The composite laminate is subjected to an external unidirectional stress of $100 \mathrm{MPa}$.

ply cracks due to the development of oxidation-induced residual stresses. These stresses are not negligible compared to those caused by CTE mismatches between the plies.

(iii) The stresses in the thermo-oxidized ply and its constituents of a composite plate subjected to transverse tension or in-plane shear (see Figs. 6 and 7) differ from those in the unaffected ply under the same external loading conditions: the macroscopic stresses increase during the thermal oxidation as a consequence of increased effective stiffness of the thermo-oxidized ply.

(iv) At the scale of ply constituents, to a first approximation, the stress concentration in the reinforcing fibers does not vary as a function of concentration of oxidation products, since the properties of carbon fibers remain unchanged during the thermal oxidation process.

(v) On the second hand, the stresses in the epoxy matrix increase during the thermal oxidation process, which can be attributed to the growing stiffness of this constituent induced by the process. Actually, composites are generally designed so that the reinforcing elements concentrate the stresses. Moreover, in practice, damage and failure initially often take place in a subsurface of mechanical parts. Thus, the increased stress in the resin of the external ply is not favorable to the durability of the composite structure. These facts explain the lower durability of thermo-oxidized composite structures compared with that of structures unaffected by oxidation.

(vi) The influence of thermal oxidation on the multiscale mechanical states of a thin composite plate is practically limited only to the oxidized ply. The first unaffected ply bordering on the oxidized one does not experience a significant evolution of its mechanical states at any scale. 

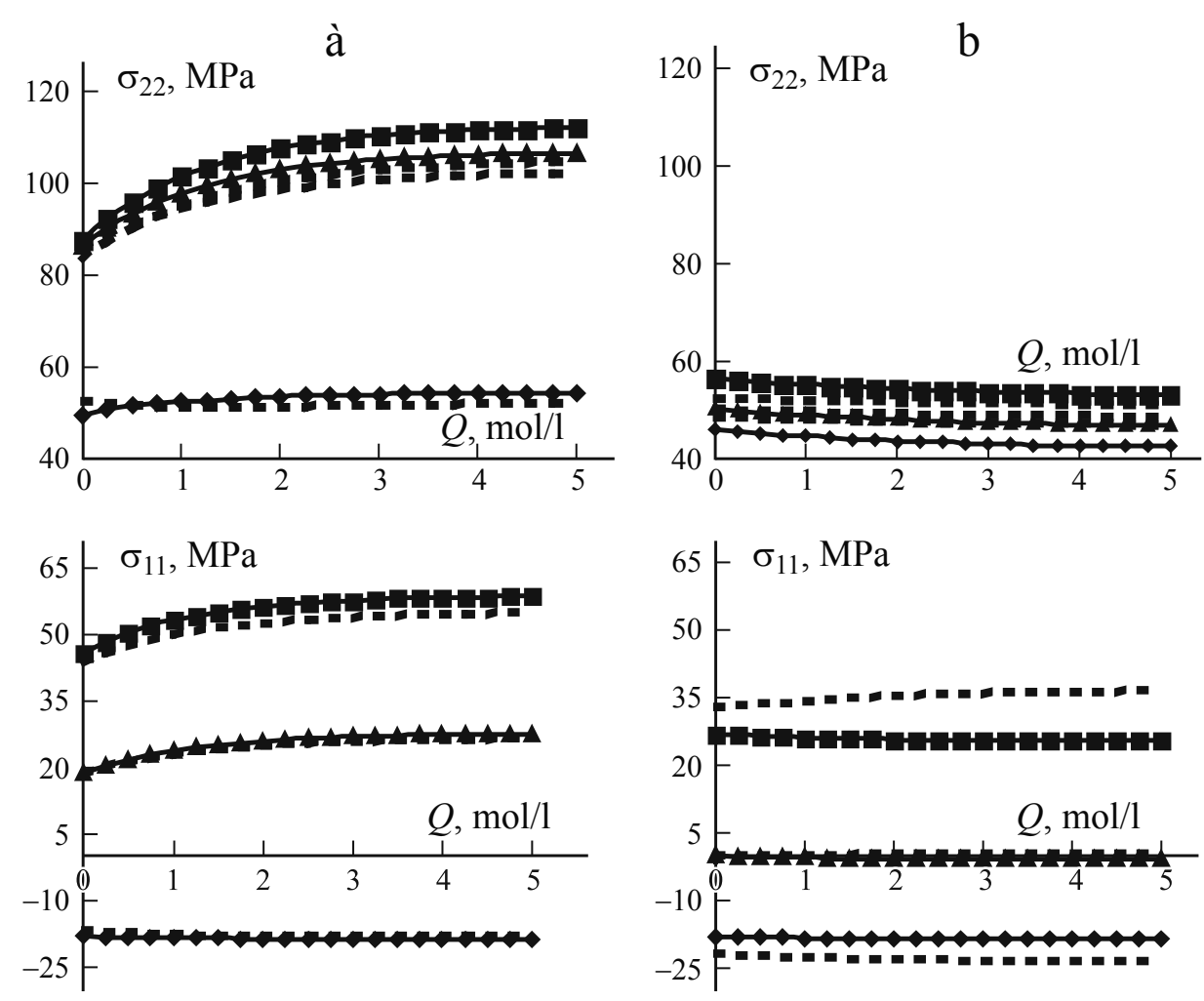

Fig. 6. The same in the case where the external longitudinal stress is $50 \mathrm{MPa}$. Designations as in Fig. 5.

à

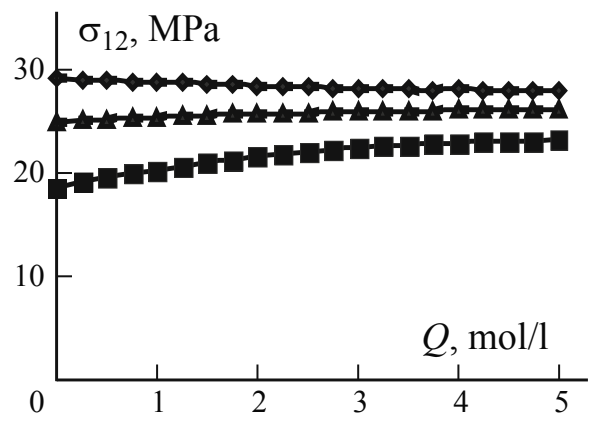

b

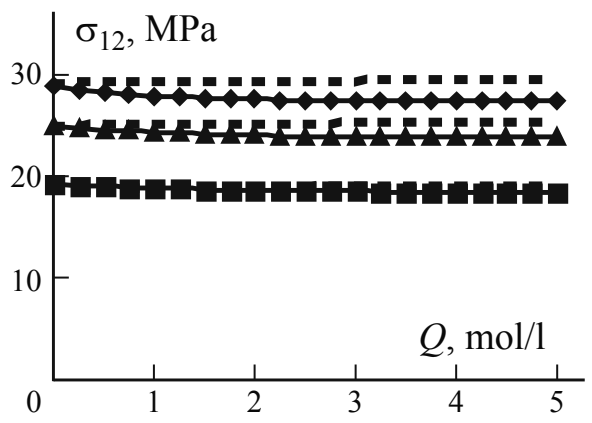

Fig. 7. The same for the shear stress $\sigma_{12}$ in the case where the composite laminate is subjected to an external shear stress of $25 \mathrm{MPa}$. Designations as in Fig. 5.

\section{Conclusions}

In this study, the consequences of thermal oxidation and shrinkage of the epoxy resin constituting a composite structure were investigated by using a scale transition approach. The results obtained are in rather good agreement with finite-element calculations and show that the effective properties and mechanical states of the external ply of a composite structure subjected to a thermal oxidation process do not strongly differ from the corresponding reference values of the ply unaffected by thermal oxidation. On the contrary, the local properties and mechanical states of the matrix constituting the ply affected by thermal oxidation and the matrix shrinkage strongly vary with the thermal oxidation process. The evolution of mechanical proper- 

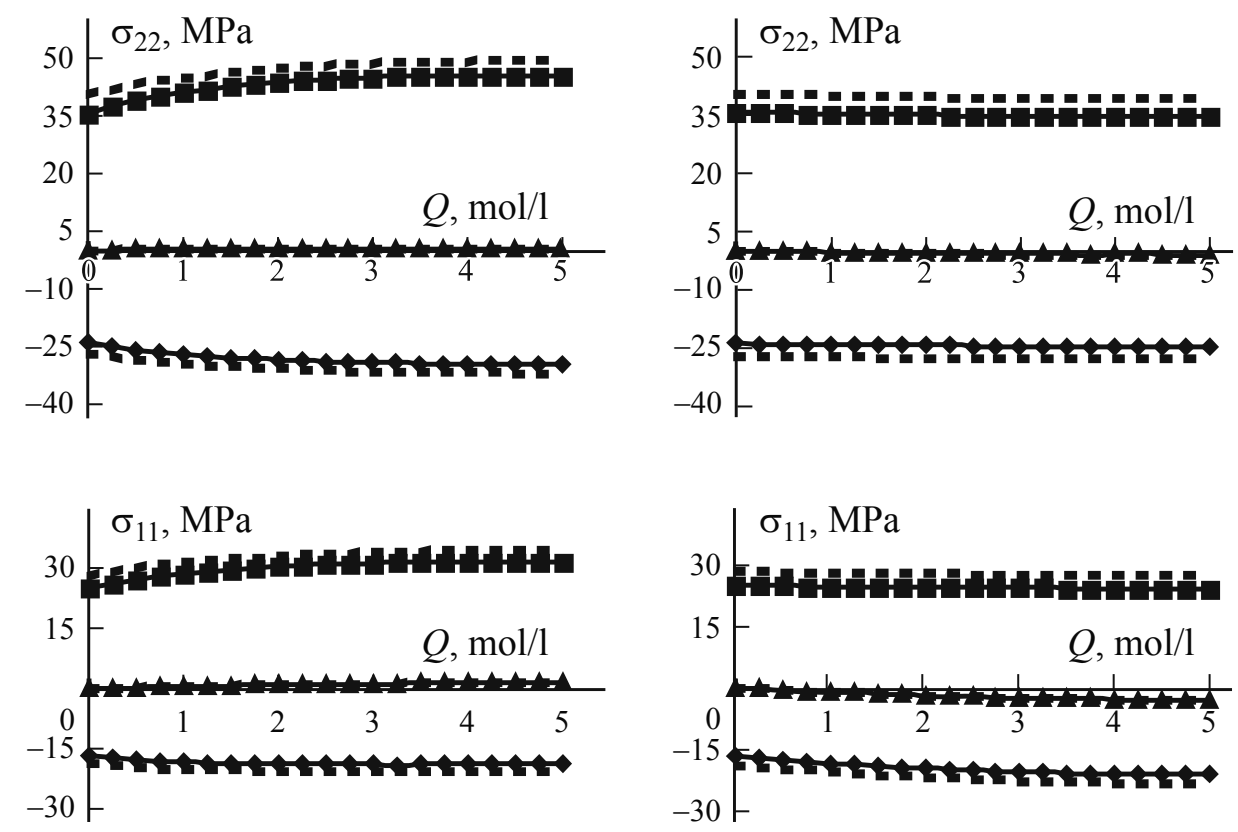

Fig. 8. The same for the longitudinal $\sigma_{11}$ and transverse $\sigma_{22}$ stresses in the case where the composite laminate is subjected to a thermal load $\Delta T=100^{\circ} \mathrm{C}$. Designations as in Fig. 5.

ties and mechanical states in the epoxy during its thermal oxidation reduces the durability of composite structures, especially in the case of action of a transverse tensile or an in-plane shear load. However, the results of our investigation do not indicate that the service life of a composite plate submitted to longitudinal or thermal loads will be significantly affected by the thermal oxidation of epoxy.

\section{Prospectives}

The scope of the present study was limited to the consequences of thermal oxidation of a polymer matrix on the evolution of mechanical properties and states of composite materials during their subsequent loading at ambient temperature. However, the composites undergoing thermal aging are often subjected to mechanical loads at elevated temperatures. Under these conditions, the polymer matrix becomes viscoelastic. This leads to a viscoelastic behavior of composite plies at the macroscopic scale. To take into account these physical phenomena, a viscoelastic scale transition model must be developed. Such a model will allow one to predict the effective thermomechanical properties (the stiffness tensor and the coefficients of thermal expansion) of composite plies as functions of time and temperature and to proceed to the localization of mechanical states in the constituents of each ply of a composite structure.

Moreover, some papers report an evolution of the yield strength of epoxies during the thermal oxidation process [42, 44]. Furthermore, a significant factor in the oxidation of resins is shrinkage due to the release of oxidation byproducts [42]. The shrinkage is eventually manifested as the origination of ply cracks due to the development of oxidation-induced residual stresses. Multiscale failure criteria enabling one to take into account these experimental results will be developed in our further investigations in order to rigorously investigate the durability of structures having been submitted to thermal oxidation processes. 


\section{REFERENCES}

1. Y. Lin, L. Ye, S. Zhongqing, and M. Guang, "Functionalized composite structures for new generation airframes: a review," Compos. Sci. Technol., 65, 1436-1446 (2005).

2. V. Bellenger, J. Decelle, and N. Huet, "Ageing of a carbon epoxy composite for aeronautic applications," Composites, Pt. B, 36, 189-194 (2005).

3. J. B. Nelson, "Thermal ageing of graphite/polyimide composites, in long-term behaviour of composites," in: T. K. O’Brien (ed.), ASTM STP-813, Philadelphia (1983), p. 206.

4. J. R. Kerr and J. F. Haskins, "Effects of 50,000 h of thermal aging on graphite/epoxy and graphite/polyimide composites," AIAA J., 22, No. 1, 96 (1984).

5. K. J. Bowles and A. Meyers, "Specimen geometry effects on graphite/PMR, 15 composites during thermo-oxidative ageing," in: 31st Int. SAMPE Symp. (1986), pp. 1285-1299.

6. P. M. Hergenrother, "Development of composites, adhesives and sealants for high-speed commercial airplanes," SAMPE J., 36, 30-41 (2000).

7. M. D. Brunner and T. Cebeci, "Development of the California State University, Long Beach composite durability laboratory,” in: Proc. Int. SAMPE Symp. Exhibit. (1994), pp. 1554-1563.

8. M. S. Madhukar, K. J. Bowles, and D. S. Papadopoulos, "Thermo-oxidative stability and fiber surface modification effects on the inplane shear properties of graphite/PMR-15 composites," J. Compos. Mater., 31, No. 6, 596-618 (1997).

9. M. C. Lafarie-Frenot, "Damage mechanisms induced by cyclic ply-stresses in carbon-epoxy laminates: environmental effects," Int. J. Fatigue, 28, 1202-1216 (2006).

10. L. Olivier, N. Q. Ho, J. C. Grandidier, and M. C. Lafarie-Frenot, "Characterization by ultra-micro indentation of an oxidized epoxy polymer: correlation with the predictions of a kinetic model of oxidation,” Polym. Degrad. Stab., 93, 489-497 (2008).

11. X. Colin and J. Verdu, "Strategy for studying thermal oxidation of organic matrix composites," Compos. Sci. Technol., 65, 411-419 (2005).

12. X. Colin, A. Mavel, C. Marais, and J. Verdu, "Interaction between cracking and oxidation in organic matrix composites," J. Compos. Mater., 39, No. 15, 1371-1389 (2005).

13. N. Rasoldier, X. Colin, J. Verdu, M. Bocquet, L. Olivier, L. Chocinski-Arnault, and M. C. Lafarie-Frenot, "Model systems for thermooxidised epoxy composite matrices," Composites, Pt. A, 39, No. 9, 1522-1529 (2008).

14. J. Wise, K. T. Gillen, and R. L. Clough, "Quantitative model for the time development of diffusion-limited oxidation profiles,” Polymer, 38, 1929-1944 (1997).

15. X. Colin, C. Marais, and J. Verdu, "A new method for predicting the thermal oxidation of thermoset matrices; application to an amine crosslinked epoxy," Polym. Test., 20, No. 7, 795-803 (2001).

16. G. P. Tandon, K. V. Pochiraju, and G. A. Schoeppner, "Modeling of oxidative development in PMR-15 resin," Polym. Degrad. Stabil., 91, 1861-1869 (2006).

17. L. Olivier, N. Q. Ho, J. C. Grandidier, and M. C. Lafarie-Frenot, "Development of experimental, theoretical and numerical tools for studying thermo-oxydation of CFRP composites," Composites, Pt. A, 40, 1008-1016 (2009).

18. M. C. Lafarie-Frenot, S. Rouquie, N. Q. Ho, and V. Bellenger, "Comparison of damage development in C/epoxy laminates during isothermal ageing or thermal cycling," Composites, Pt. A, 37, 662-671 (2006).

19. J. M. Sprauel and L. Castex, in: First European Powder Diffraction International Conference on X-Ray Stress Analysis, Munich (1991).

20. W. Voigt, Lehrbuch der Kristallphysik, Teubner, Leipzig-Berlin (1928).

21. A. Reuss, "Berechnung der Fliessgrenze von Mischkristallen auf Grund der Plastizitätsbedingung für Einkristalle," $Z$. Angew. Math. Mech., 9, 49-58 (1929).

22. H. Neerfeld, “Zur Spannungsberechnung aus röntgenographischen Dehnungsmessungen,” Mitt. Kaiser-Wilhelm-Inst. Eisenforschung Düsseldorf, 24, 61-70 (1942).

23. R. Hill, "The elastic behaviour of a crystalline aggregate," Proc. Phys. Soc., 65, 349-354 (1952). 
24. S. W. Tsai and H. T. Hahn, Introduction to Composite Materials, Technomic Publ. Co., Inc., Lancaster, Pennsylvania (1980).

25. K. Tanaka and T. Mori, "The hardening of crystals by non-deforming particles and fibers," Acta Metall., 18, 931-941 (1970).

26. T. Mori and K. Tanaka, "Average stress in matrix and average elastic energy of materials with misfitting inclusions," Acta Metall., 21, 571-574 (1973).

27. F. Jacquemin, S. Fréour, and R. Guillen, "A hygro-elastic self-consistent model for fiber-reinforced composites," J. Reinf. Plast. Compos., 24, 485-502 (2005).

28. S. Fréour, F. Jacquemin, and R. Guillén, "Extension of Mori-Tanaka approach to hygroelastic loading of fiber-reinforced composites - Comparison with Eshelby-Kröner self-consistent model,” J. Reinf. Plast. Compos., 25, 1039-1052 (2006).

29. J. D. Eshelby, "The determination of the elastic field of an ellipsoidal inclusion, and related problems," Proc. Roy. Soc., A241, 376-396 (1957).

30. E. Kröner, "Berechnung der elastischen Konstanten des Vielkristalls aus des Konstanten des Einkristalls," Z. Phys., 151, 504-518 (1958).

31. R. Hill, "Continuum micro-mechanics of elastoplastic polycrystals", J. Mech. Phys. Solids, 13, 89-101 (1965).

32. R. Morris, "Elastic constants of polycrystals," Int. J. Eng. Sci., 8, 49 (1970).

33. U. F. Kocks, C. N. Tomé, and H. R. Wenk, Texture and Anisotropy, Cambridge Univ. Press (1998).

34. T. Mura, Micromechanics of Defects in Solids, Martinus Nijhoff Publ., The Hague, Netherlands (1982).

35. H. L. McManus and R. A. Cunningham, "Materials and mechanics analyses of durability tests for high-temperature polymer matrix composites," in T. S. Gates and A.-H. Zureick (eds.), High Temperature and Environmental Effects on Polymeric Composites. Vol. 2, ASTM STP 1302 (1997), p. 1.

36. K. V. Pochiraju, G. P. Tandon, and G. A. Schoeppner, "Evolution of stress and deformations in high-temperature polymer matrix composites during thermo-oxidative aging," Mech. Time-Depend. Mater., Springer Science, 12, Iss. 1, 45-68 (2007).

37. K. J. Bowles, M. S. Madhukar, D. S. Papadopoulos, L. Inghram, and L. McCorkle, "The effect of fiber surface modification and thermal aging on composite toughness and its measurement," J. Compos. Mater., 6, 552-579 (1997).

38. P. D. Soden, M. J. Hinton, and A. S. Kaddour, "Lamina properties lay-up configurations and loading conditions for a range of fiber-reinforced composite laminates," Compos. Sci. Technol., 58, 1011-1022 (1998).

39. B. P. Patel, M. Ganapathi, and D. P. Makhecha, "Hygrothermal effects on the structural behaviour of thick composite laminates using higher-order theory," Compos. Struct., 56, 25-34 (2002).

40. C. Henaff-Gardin, S. Rouquie, M. C. Lafarie-Frenot, and D. Bertheau, "Fissuration matricielle induite par des contraintes cycliques dans des stratifies croises carbone/epoxyde," Rev. Compos. Matér. Av., 11-13, 383-413 (2001).

41. M. C. Lafarie-Frenot and S. Rouquie, "Influence of oxidative environments on damage in c/epoxy laminates subjected to thermal cycling," Compos. Sci. Technol., 64, 1725-1735 (2004).

42. J. Decelle, N. Huet, and V. Bellenger, "Oxidation induced shrinkage for thermally aged epoxy networks," Polym. Degrad. Stab.., 81, 239-248 (2003).

43. S. Fréour, F. Jacquemin, and R. Guillén, "On an analytical self-consistent model for internal stress prediction in fiber-reinforced composites submitted to hygroelastic load," J. Reinf. Plast. Compos., 24, 1365-1377 (2005).

44. T. Sinmazcelik and T. Yilmaz, "Thermal aging effects on mechanical and tribological performance of PEEK and short fiber reinforced PEEK composites,” Mater. Design, 28, 641-648 (2007). 